A Market-Based Approach for Partner Selection in Marketing Alliances

Chekitan S. Dev

Cornell University

Saul Klein

National University of Singapore

Reed A. Fisher

Cornell University 
Chekitan Dev is an Assistant Professor of Marketing in the School of Hotel

Administration at Cornell University.

Saul Klein is a Senior Fellow in Marketing at the National University of

Singapore.

Reed Fisher is a doctoral candidate in the School of Hotel Administration at

Cornell University.

The authors thank Michael Morgan for his helpful comments and suggestions.

They also gratefully acknowledge support for this study from the School of Hotel

Administration Summer Research Program and the Cornell Center for Hospitality

Research. 


\begin{abstract}
The travel and tourism industry has witnessed the formation of a number of marketing alliances in the recent past and these are expected to continue. A critical concern is how should one select a marketing partner. This article provides a starting point for answering this question with a market-driven approach based on customer usage complementarity.
\end{abstract}




\section{A Market-Based Approach for Partner Selection in Marketing Alliances}

Much attention has been devoted in recent years to the concept of alliances and the need for businesses to cooperate in order to be competitive (Badaracco 1991;

Business Week 1993; Ohmae 1989). Global competition, information technology, and increased customer sophistication call for new forms of organization. Pressure to survive in an increasingly competitive environment with limited capital has led companies to explore alliances, networks, and other hybrid organization arrangements as alternatives to the more traditional internal development, merger, and acquisition approaches (Oliver 1990).

The travel and tourism industry has had a long history of marketing alliances. For example, in the 1940s InterContinental Hotels had developed alliances with a number of airlines including Pan Am (its parent), British Airways; Lufthansa, and Swissair (Lane 1986). The pace of alliance formation has accelerated, however, in recent years. The process of change in the tourism market requires firms to reassess their channel configuration in order to remain competitive (Go and Williams 1994). Alliances can build 
competitive advantage through speed and flexibility, and hotels, airlines, and car rental companies are linking up in order to gain competitive advantage.

The increased attention to alliances comes from a growing recognition of the benefits of coordination of travel services, together with an increasing appreciation of the difficulties in achieving these benefits under a single corporate umbrella. For example, in the mid-1980s United Airlines created Allegis, an integrated travel supply organization with Hertz Car Rental, United Airlines, and Westin Hotels, all under common ownership (Willard, Schoenecker, and Kreuger 1990). United's efforts to achieve synergies and offer greater benefits at lower costs failed. The intended benefits proved difficult to attain and costly to achieve.

\section{Travel and Tourism Industry}

Travel and tourism is among the world's largest industries and the greatest generators of jobs worldwide. The World Travel and Tourism Council reported in-1993 that tourism would generate more than 200 million jobs in 1994, accounting for one in nine workers worldwide (Travel Management Daily 1993). 
Alliance formation in the global travel and tourism industry increased throughout the 1980s. By the early 1990s most of the world's major airline, hotel, and car rental firms were linked by a web of cross-shareholdings, joint ventures, and joint sales and service arrangements (Business Week 1992; Dev and Klein 1993). This increase in alliance activity is a response to increased uncertainty about demand and competition. Demand uncertainty due to market saturation and resulting excess capacity in both North America and Europe has increased the pressure on firms to expand the size and scope of their markets.

Competitive uncertainty is high for three reasons. First, the industry is concentrated enough for competitive interdependence to come into play. As of 1991, the top three airlines accounted for $51.4 \%$ of global market share (Market Share Reporter 1992), the top three hotel companies accounted for $64.9 \%$ of global market share, and the top three car rental companies accounted for $61.4 \%$ of global market share (Market Share Reporter 1993). Second, increasing globalization of the industry is destabilizing the competitive environments in many once-protected national markets. 
Historically, the rules of the game were well established in most national markets, the majority of which were tightly knit oligopolies or duopolies. New entrants, however, have increased the intensity of competition and broken down previously well established competitive understandings. Third, the entry of Asian and European hotel firms into the North American market and the entry of American airline, hotel, and car rental firms into Europe and Asia have resulted in a significant increase in the number of competitors and the range of product offerings in all three regions. Under these conditions, finding the right partner for a marketing alliance becomes a key determinant of market success.

\section{Theoretical Background}

In a general sense, marketing alliances are defined in terms of synergistic or

symbiotic relationships between two or more independent entities (Adler 1966;

Varadarajan and Rajaratnam 1986), that is, an alliance of resources designed to

increase the market potential of all entities involved. Successful marketing alliances can

add value for the customer in a competitive context. Furthermore, alliances may be 
seen as a value-adding effort on the part of the firm that affords fresh opportunities for building and maintaining competitive advantage (Bucklin and Sengupta 1993). In the airline industry, for example, route- and code-sharing arrangements between international airlines provide overseas travelers with the advantages of multiple purchase options coupled with the convenience of seamless, one-stop shopping.

Alliances have been viewed from a variety of perspectives, including that of firm internationalization (Beamish and Banks 1987), transaction cost economics (Parkhe 1993), networks (Jarillo 1988), organizational learning (Hamel 1992), game theory (Parkhe 1993), developmental processes (Ring and Van de Ven 1994), and ethics (Gundlach and Murphy 1993). Much of this research has focused on risk, fixed costs, economies of scale, and access to distribution as motivations for alliance formation. '

What is lacking is an appreciation for the centrality of the customer in the conceptualization, design, and -management of marketing alliances. Peter Francese, president of American Demographics, recently commented (conversation with first author, February 11,1994$)$ that although an increasing number of companies are 
forming such alliances they are doing so for the wrong reasons. "The customer," he lamented, "is being ignored in all this."

While there has been growing interest in the subject of alliances, there has also been growing disenchantment with them. Industry observers suggest that most alliances fall short of expectations or are disbanded (Levine and Byrne 1986). While some of these failures may be attributed to changes in business conditions, inappropriate partner selection underlies a number of alliance failures (Carey 1994).

While studies have found organizational compatibility to be an important determinant of marketing alliance success (Bucklin and Sengupta 1993; Spekman and Sawhney 1990), they do not address the partner selection issue. In an exception, Varadarajan and Rajaratnam (1986) proposed that marketing alliances (as opposed to alliances formed for technological or financial reasons) be conceptualized, designed, and managed from the perspective of the customer. They recommend that the usage complementarity that exists between goods and services be used as a basis for 
determining partner selection. In an attempt to contribute to the ongoing field of enquiry in this area, this article offers an innovative approach to address this issue.

\section{Alliances and Customer Usage Complementarity}

There are two generally accepted motivations for alliance formation: efficiency and effectiveness (Jarillo 1988). Efficiency objectives of an organization involve exploiting cost-reduction opportunities by forming alliances with other companies that have a complementary expertise. Costs are reduced through sharing production technologies or by taking advantage of scale economies in distribution. Cost-based motivations are also intended to provide competitive advantage through lower price and consequently enhanced customer value.

The effectiveness objectives of an organization involve market-based motivations to increase market share and size. Given increased competitive intensity, fragmented market segments, and an increasing emphasis on leveraging one's core competence, firms seek to increase their market share and/or size through nontraditional means. The 
alliance between United and Lufthansa Airlines is an example of such a market-size alliance. By utilizing a market-driven approach to alliance formation based on customerusage complementarity, efficiency and effectiveness can be addressed simultaneously.

As Bucklin and Sengupta (1993) found, appropriate partner match offers the greatest opportunity for alliance effectiveness. With the elaborate web of alliances developing in the travel and tourism industries, the appropriateness of partner selection has a critical impact on alliance success.

Opportunities for alliances that seek to capitalize on usage complementarity may be conceptualized in two ways: those that bridge gaps in product-market coverage and those that bundle complementary products and services. (The concepts of bundling and bridging are adapted from Farquhar et al. [1992].) Bridging alliances provide value to consumers by expanding the coverage of existing firms, either geographically or demographically, as well as by reducing costs through scale effects. Alliances between major airlines and feeder carriers are examples of bridging relationships. Bundling alliances provide value to consumers by creating seamless, one-stop shopping 
opportunities that reduce search and transaction costs. Alliances between airline, hotel, and car rental companies are examples of bundling relationships. These two types of alliances are not mutually exclusive, and it is easy to envisage an alliance having both features. For analytic clarity, however, they are examined separately here, without any loss of applicability.

In their discussion of symbiotic marketing, Varadarajan and Rajaratnam (1986) suggest that by studying product- and service-usage complementarity firms can capitalize on existing or potential complementarity patterns to promote new relationships. To support their proposition they use a hypothetical example from the travel and tourism industry in which a traveler uses an American Express card to fly Eastern Airlines, rent an Avis car, and stay at a Holiday Inn, all at special rates (Varadarajan and Rajaratnam 1986, p.15). This study builds on their work by using empirical data to show how opportunities for marketing alliances may be examined in the travel and tourism industry. 


\section{Method}

The data were obtained from the Longwoods Travel USA study of the U.S.

pleasure traveler (Longwoods International 1990), conducted in early 1990. The main purpose of the study was to identify the size and structure of the U.S. pleasure travel market.

In the first phase, questionnaires were mailed to a randomly selected sample of 3,050 households drawn from NFO Research Inc.'s consumer panel in each of the nine U.S. census The data were obtained from the Longwoods Travel USA study of the U.S. pleasure traveler (Longwoods International 1990), conducted in early 1990. The main purpose of the study was to identify the size and structure of the U.S. pleasure travel market. In the first phase, questionnaires were mailed to a randomly selected sample of 3,050 households drawn from NFO Research Inc.'s consumer panel in each of the nine U.S. census divisions (excluding residents of Alaska and Hawaii), for a mail-out of 27,450 surveys. Respondents within any household were randomly chosen using the next birthday selection method. (The questionnaire was addressed to the member of the 
household, 18 years or older, who had the next birthday.) A total of 18,379 completed questionnaires were received, for a $67 \%$ completion rate. The questionnaire obtained information on the following areas of interest: destinations visited; number of trips taken during the past year; duration of trips; intention to travel over the next two years; magazine readership; participation in various sports, leisure, and cultural activities; and demographic information. Of these respondents, 15,094 indicated that they had taken at least one overnight pleasure trip in the previous 12 months.

In the second phase, the 15,094 individuals in the subset of trip takers were sent a follow-up questionnaire asking specific questions about their most recent trip. From these individuals, a total of 12,098 completed questionnaires were received, for a response rate of $86 \%$. This high response rate was attributable to three factors: (1) people enjoy reminiscing about their travel, (2) a gift was offered as an incentive for completing the survey, and (3) surveys were personalized with reference to the specific trip elicited in phase one. Respondents identified airline, rental car, and hotel brands used on this specified trip. This information was tabulated for the statistical analysis. 


\section{Statistical Technique}

Correspondence analysis (CA) was used to analyze and summarize the associations among the sets of data. CA is a multivariate descriptive statistical technique useful for analyzing categorical tabular data. This method is particularly useful since the analysis converts the data into graphical displays (maps) and also provides numerical statistics. CA is invaluable in understanding the relationships existing within the tables. CA is known as an exploratory technique and is intended to reveal the features in the data. In CA there are no assumptions about the underlying distribution of the data. The only requirement for CA is that a potential relationship among the variables of interest exists.

The coordinates obtained from the analysis are analogous to those derived from a principal components analysis except that CA partitions the total chi-square for the cross-tabular data. The coordinates are based on chi-square distances that measure how far the row profiles and the column profiles are from their average profiles. 
Eigenvalues are obtained from the singular-value decomposition of the correspondence matrix and can be used to determine the reduced space in which to represent the data.

The analysis used three CA algorithms (Carroll, Green, and Schaffer 1986;

Greenacre 1984; Lebart, Morineau, and Warwick 1984) to analyze the data. All three techniques produced similar graphical displays. While distances within sets (i.e., distances among the column variables and distances among the row variables) can be interpreted in CA, there is some debate as to whether interpoint distances (i.e., the distances between row and column variables) can be interpreted directly (Carroll, Green, and Schaffer 1986, 1987, 1989; Greenacre 1989). As the focus of this study was on the relative positioning of the variables to one another (rather than exact positioning), interpoint distance interpretation was considered to be appropriate. Interpoint distances make sense because the study was interested in those firms that are close to other firms. The study did not attempt to determine which firms are closer in-any absolute sense, nor did it attach statistical significance to any of the distance estimates. Details 
of CA can be found in Greenacre (1984), Hoffman and Franke (1986), and Lebart,

Morineau, and Warwick (1984)

\section{Results and Managerial Implications}

To illustrate the usefulness of customer usage complementarity, we first looked

for complementary relationships across product categories, among airline, hotel, and

car rental brands (i.e., bundling alliances). Second, we looked for complementarity

within a product category (i.e., bridging alliances). The hotel product category was

chosen since it has the greatest number of differentiated brands positioned at different

quality and price levels in the market. Chi-square as well as likelihood ratio and Fisher's

exact tests for independence showed relationships do exist among the variables

analyzed ( $p<.01$ for all tests). Since Pearson's chi-square test is sensitive to sample

size we also measured the association among the variables using the likelihood ratio

statistic as well as Fisher's exact test. Both tests confirmed that a relationship is present 
among the variables $(p<.001$ and $p<.002$ respectively). (The authors thank one of the

reviewers for pointing this out.)

\section{Bundling Alliances}

We first analyzed the customer usage patterns among nine hotel brands, four car rental brands, and four airline brands (these brands are the only ones for which sufficient cross-product usage data were obtained). Results are based on 687 respondents. Analytic results are provided in Table 1. The two axes account for approximately $91 \%$ of the variability in the data set. The graphical results of the correspondence analysis for cross-product category usage are shown in Figure 1.

In assessing potential relationships, the figure can be used in two ways, depending on the strategic objective for the alliance. For those firms following a market penetration strategy seeking to increase their market share, the recommended solution would be to cement relationships with other firms in close proximity on the grid, indicating high usage complementarity. United Airlines would be advised to team up with Avis and either Holiday Inn or Best Western. Similarly, Delta might choose Alamo 
and Hilton or Howard Johnson. For firms following a market development strategy, seeking to increase the size of their served market, the recommendation would be to establish closer relations with partners in the other product categories that are currently not used complementarity (i.e., not in close proximity). The choice of partner will depend on the type of customer that is being targeted. For example, Sheraton might choose either Alamo or Hertz for market expansion.

In the airline industry, one very successful means to hold and/or build market share by capitalizing on customer-usage complementarity has been through the creation of frequent flyer programs with hotel and rental car partners. Until now, alliances between airlines, car rental, and hotel companies have been largely limited to their membership in each other's frequent traveler programs. The potential exists for much deeper cooperation and the creation of quasi-integrated travel service providers, resulting in enhanced benefits for customers. The benefits of integrated travel products that bundle airline, hotel, and car rental services into one seamless package of enhanced value have been recognized for some time "Package tours" in the leisure 
market, offering value through lower price and lower search costs, represent a limited

form of such cooperation.

When these data were collected, United Airlines had no relationship with Avis, Holiday Inn, or Best Western. Delta Air Lines had a relationship with the Alamo and Avis car rental companies and with Hilton Hotels. Sheraton Hotels was in United Airline's and American Airline's frequent flyer programs. Marriott Hotels had an aggressive marketing alliance with Hertz Rent A Car.

\section{Bridging Alliances}

The hotel product category was chosen to illustrate bridging alliances. Customer usage patterns between 10 hotel brands indicated as the first choice and 19 hotel brands reported as a second choice were the focus of the second analysis. Of the three product categories, the hotel category has the greatest number of differentiated brands positioned at different quality and price levels in the market, unlike airlines and car rental brands that tend to be fairly interchangeable. Results are based on 1,047 
respondents listing two or more hotel brands used on a particular trip. Analytic results are provided in Table 2.

The two axes account for approximately $60 \mathrm{I}$ of the variability in the data set. The graphical results of the correspondence analysis for within-product-category relationships are shown in Figure 2. Brands in capital letters (e.g., "HILTON") represent the first hotel brand used by the traveler. Brands in lowercase letters (e.g., "hilton") represent the second brand used.

In the hotel industry, there are three generally recognized product tiers: upscale (e.g., Hilton, Hyatt, or Sheraton), midscale (e.g., Holiday Inn or Ramada), and economy (e.g., Days Inn, Super 8, or Motel 6). With three tiers of product quality, there could theoretically be three positions for each hotel (first, second, and third choice). The data, however, show that leisure travelers generally do not trade up or down more than one tier.

For those firms seeking to penetrate existing markets, alliances with firms in close proximity, except those that have the same geographical locations (to avoid 
cannibalization), make the most sense. In the illustration, we see "HILTON" listed close to direct up-market competitors "hyatt" and "sheraton" which are second hotels used by Hilton customers. If these chains had different geographic coverage, alliances would make sense for market penetration. An example of a similar sort is the alliance, before they merged, between Regent Hotels (Hong Kong) and Four Seasons (Canada). We also see "hilton" positioned close to "COMFORT" (a mid-market choice), indicating that Hilton was a second choice for Comfort Inn customers and that an alliance between the two hotels would enhance market penetration.

For those firms seeking to develop new markets, alliances with others not in close proximity make the most sense. Hyatt (up-market) could cooperate with either Comfort Inn or Hampton Inn (mid-market) for market development. A midmarket hotel could choose to affiliate with another hotel in the same tier (but with different geographic coverage) to give its customers more locations from which to choose, or with hotels in upper or lower tiers to give its customers choices for different occasions when budgetary or other considerations differ. 


\section{Limitations}

A few limitations in the study need to be addressed in further research. First, the usage patterns identified above are for leisure travelers and may differ from what we would find for business travelers. The difference, however, may be a lesser problem in this industry since consumers are likely to be in both the business and leisure segments depending on the occasion. Second, it is not known whether the usage patterns found are the consequence of existing cooperative behavior. To evaluate alliance success over time, longitudinal data are required. Finally, all data needed for the identification of customer-based alliance partners may not be currently available in the public domain, and this may create a barrier to firms using this methodology. This latter problem, however, may be alleviated in the future as third-party vendors, such as Claritas, develop more complete consumer databases to include multiple producer category and brand shopping behavior (conversation between first author and Mark Capaldini, executive vice president of Claritas, February 16, 1994). 


\section{Conclusions}

Complementarity in usage patterns offers a powerful way to conceptualize and develop marketing alliances. To take advantage of this approach, managers need a more complete understanding of the purchase behavior of their customers, as a basis for making better decisions about selection of partners for marketing alliances.

Therefore, a firm's most valuable asset for maximizing market potential is knowledge regarding its customers' usage of other brands in the same product class, as well as in complementary and substitute product classes (Bessen 1993).

This technique may be applied by managers of any size firm. All that is needed is information on the customer base. Furthermore, the manager can collect this data at several different times and see how the relative positioning of the firms have changed on the CA map.

The ultimate effectiveness of this method can be evaluated by comparing prealliance and postalliance market penetration and share measures. Despite the .lack 
of data to fully substantiate our method, there is compelling logic for the argument presented. New products developed and marketed through product-based alliances have little chance of success if no additional value is created for the customer or if the managers do not know how to exploit the value of their market potential by developing profitable alliances. By identifying symbiotic partners based on customer-usage complementarity firms can supplement their product offerings and overcome the constraints that may limit their market potential. 


\section{References}

Adler, Lee (1966). "Symbiotic Marketing." Harvard Business Review, 44 (NovemberDecember): 59-71.

Badaracco Jr., Joseph L. (1991). The Knowledge Link: How Firms Compete through Strategic Alliances. Boston: Harvard Business School Press.

Beamish, Paul W., and John C. Banks (1987). "Equity Joint Ventures and the Theory of the Multinational Enterprise." Journal of International Business Studies, 18 (Summer): 1-16.

Bessen, Jim (1993). "Riding the Marketing Information Wave." Harvard Business Review, 71 (September-October): 150-60.

Bucklin, Louis P., and Sanjit Sengupta (1993). "Organizing Successful Co-marketing Alliances." Journal of Marketing, 57 (April): 32-46.

Business Week (1992). "The Airline Mess." July 6: 50-55. (1993). "The Virtual Corporation." February 8: 98-102. 
Carey, Susan (1994). "Cross-border Linkups Bring Airlines Range but Uncertain Benefits." Wall Street Journal, June 7, p. Al.

Carroll, J. Douglas, Paul E. Green, and Catherine M. Schaffer (1986). "Interpoint Distance Comparisons in Correspondence Analysis." Journal of Marketing Research, 23 (August): 271-80.

(1987). "Comparing Interpoint Distances in Correspondence Analysis: A Clarification." Journal of Marketing Research, 24 (November): 445-50. (1989). "Reply to Greenacre's Commentary on the Carroll-Green- Schaffer Scaling of Two-Way Correspondence Analysis Solutions." Jounral of Marketing Research, 26 (August): 366-68.

Dev, Chekitan S., and Saul Klein (1993). "Strategic Alliances in the Hotel Industry." Cornell Hotel and Restaurant Administration Quarterly, 34 (February): 42-45.

Farquhar, Peter H., Hulia Y. Han, Paul M. Herr, and Yuji ljiri (1992). "Master Brands." Marketing Research, 4 (September): 32-40. 
Go, Frank M., and A. Paul Williams (1994). "Competing and Cooperating in the Changing Tourism Channel System." Journal of Travel and Tourism Marketing, 2 (2/3): 229-48.

Greenacre, Michael J. (1984). Theory and Application of Correspondence Analysis.

London: Academic Press.

(1989). "The Carroll-Green-Schaffer Scaling in Correspondence Analysis: A

Theoretical and Empirical Appraisal." Journal of Marketing Research, 26

(August): 358-65.

Gundlach, Gregory T., and Patrick E. Murphy (1993). "Ethical and Legal Foundations of Relational Marketing Exchanges." Journal of Marketing. 57 (October): 35-46.

Hamel, Gary (1992). "Competition for Competence and Inter-partner Learning within International Strategic Alliances." Strategic Management Journal, 12 (Summer):

83-103. 
Hoffman, Donna L., and George R. Franke (1986). "Correspondence Analysis:

Graphical Representation of Categorical Data in Marketing Research." Journal of Marketing Research, 23 (August): 213-27.

Jarillo, J. Carlos (1988). "On Strategic Networks." Strategic Management Journal, 9 (1):

$31-41$.

Lane, Harold E. (1986). "Marriages of Necessity: Airline-Hotel Liaisons." Cornell Hote/ and Restaurant Administration Quarterly, 27 (May): 72-79.

Lebart, Ludovic, Alain Morineau, and Kenneth M. Warwick (1984). Multivariate Descriptive Statistical Analysis: Correspondence Analysis and Related Techniques for Large Matrices. New York: John Wiley and Sons.

Levine, Jonathan, and John A. Byrne (1986). "Corporate Odd Couples." Business Week, July 21: 100-5.

Longwoods International (1990). U.S. Pleasure Travel Market Study. Toronto: Longwoods International. 
Market Share Reporter (1992). Detroit: Gale Research, p. 369.

(1993). Detroit: Gale Research, pp. 481, 516.

Ohmae, Kenichi (1989). "The Global Logic of Strategic Alliances." Harvard Business

Review, 67 (March-April): 143-54.

Oliver, Christine (1990). "Determinants of Interorganizational Relationships: Integration and Future Directions." Academy of Management Review, 15 (2): 241-65.

Parkhe, Arvind (1993). "Strategic Alliance Structuring: A Game Theoretic and Transaction Cost Examination of Interfirm Cooperation." Academy of Management Journal, 36 (August): 794-829.

Ring, Peter S., and Andrew H. Van de Ven (1994). "Developmental Processes of Cooperative Interorganizational Relationships." Academy of Management Review, 19 (January): 90-118. 
Spekman, Robert E., and Kirti Sawhney (1990). "Toward a Conceptual Understanding of the Antecedents of Strategic Alliances." Marketing Science Institute, Report No. $90-114$.

Travel Management Daily (1993). New York: Official Airline Guides (October 5): 8.

Varadarajan, P. "Rajan," and Daniel Rajaratnam (1986). "Symbiotic Marketing Revisited." Journal of Marketing, 50 (January): 7-17.

Willard, Gary E., Tim Schoenecker, and David Kreuger (1990). "Allegis Corp.-1987." Proceedings of the North American Case Research Association, 4, p. 90. 
Table 1. Cross-product customer usage: airline, hotel, and car rental brands.

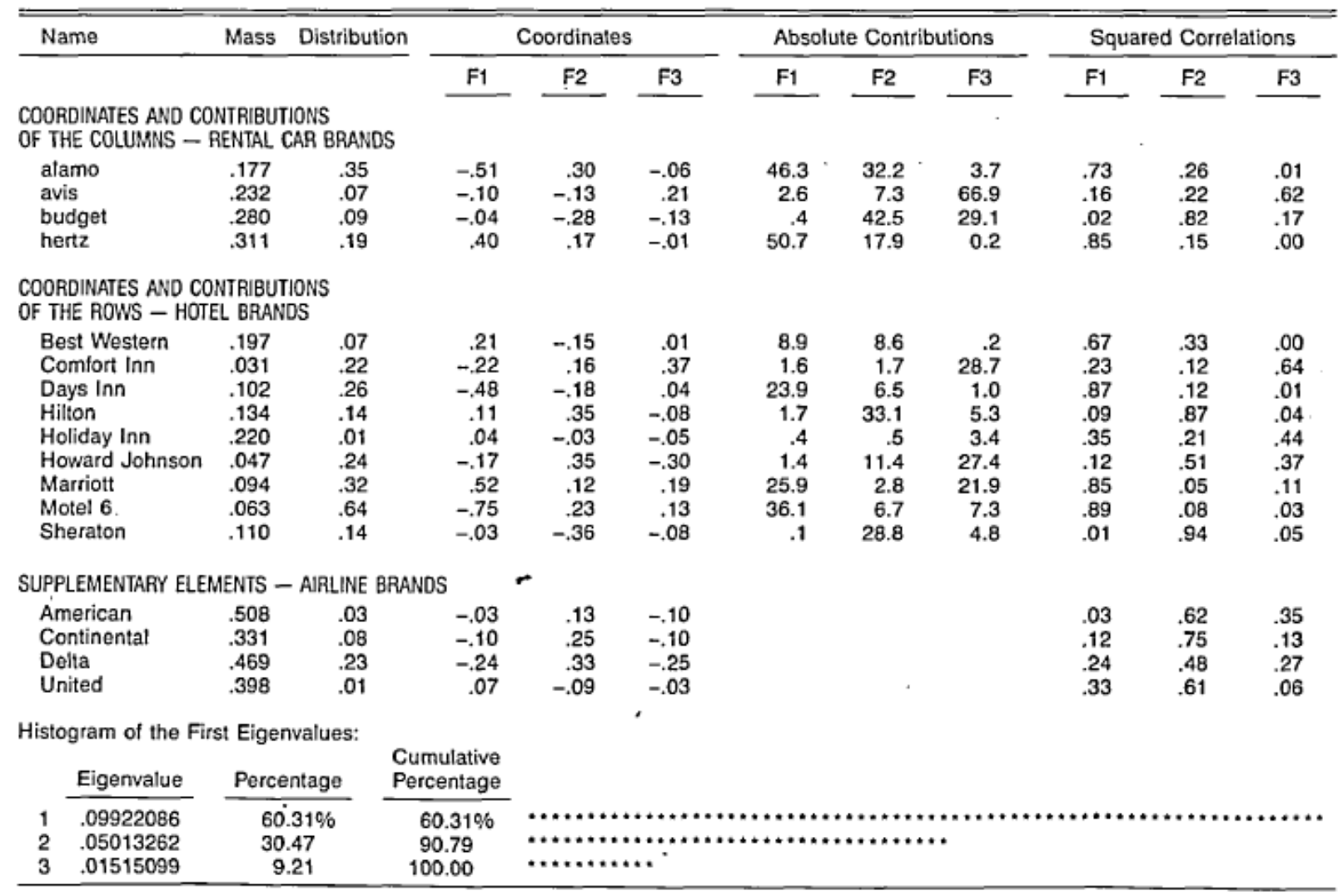


Table 2. Within-product customer usage: hotel brands.

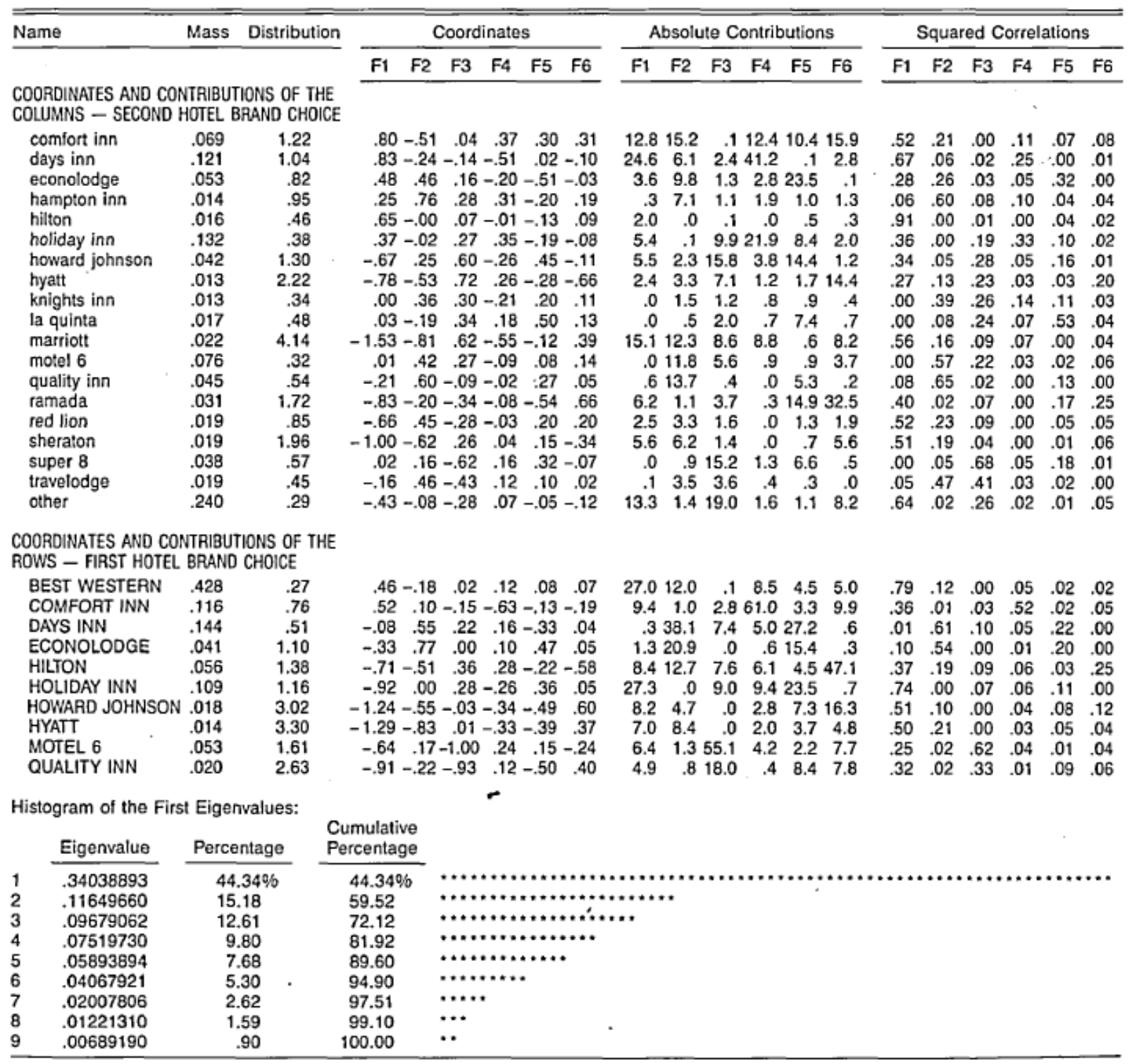




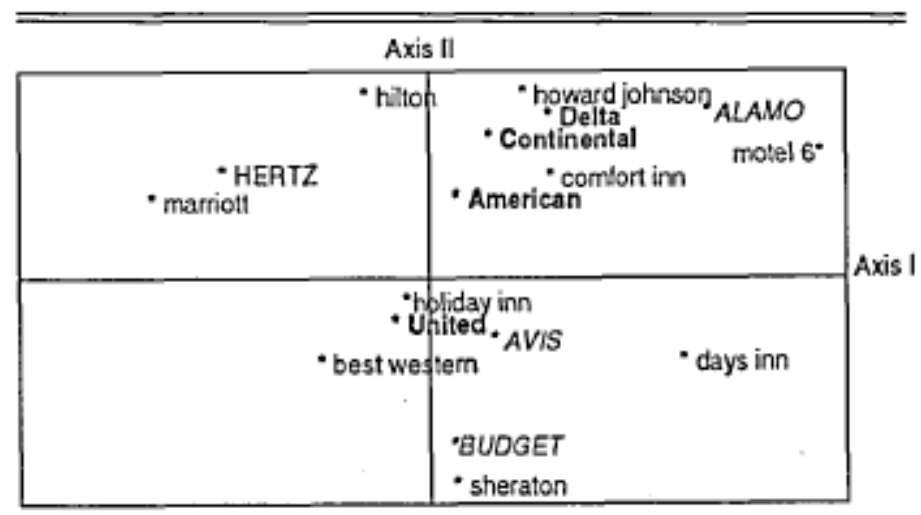

Variance explained: Axis $\mathrm{I}=.603$, Axis $\mathrm{II}=.305$.

Note: Those companies in bold letters represent airline brands, those in lowercase letters represent hotel brands, and those in italicized capital letters represent car rental brands.

Figure 1. Cross-product customer usage: airline, hotel, and car rental brands. 


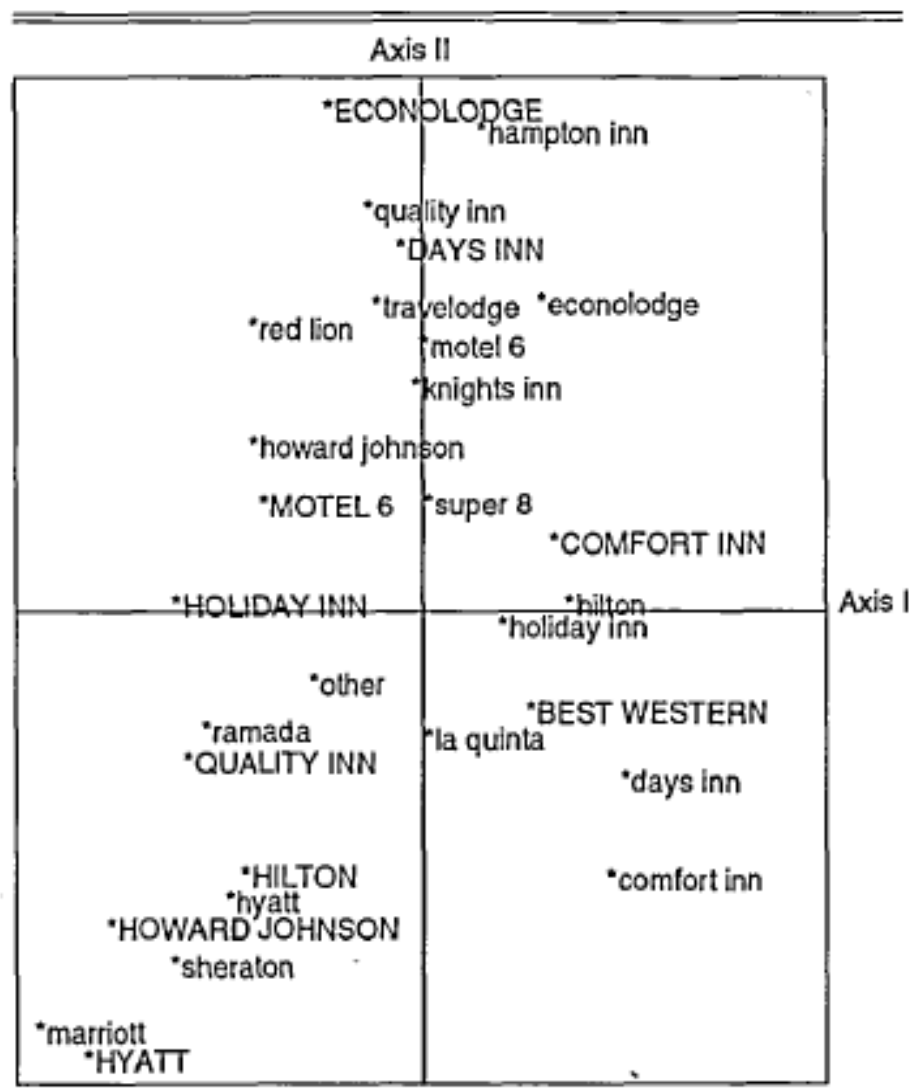

Variance explained: Axis I $=.443$, Axis II $=.152$.

Note: Those companies in capital letters represent first hotel brand used and those in lowercase letters represent second hotel brand used.

Figure 2. Within-product customer usage: hotel brands. 